\title{
An improved CE/SE scheme for numerical simulation of gaseous and two-phase detonations
}

\author{
Gang Wang ${ }^{\mathrm{a}, \mathrm{b}}$, Deliang Zhang ${ }^{\mathrm{a}, \mathrm{b}}$, Kaixin Liu ${ }^{\mathrm{a}, *}$, Jingtao Wang ${ }^{\mathrm{a}}$ \\ ${ }^{a}$ LTCS and College of Engineering, Peking University, Beijing, China \\ ${ }^{\mathrm{b}}$ LHD, Institute of Mechanics, Chinese Academy of Sciences, Beijing, China
}

\section{A R T I C L E I N F O}

\section{Article history:}

Received 3 December 2008

Received in revised form 28 July 2009

Accepted 28 July 2009

Available online 6 August 2009

\begin{abstract}
A B S T R A C T
A new structure of solution elements and conservation elements based on rectangular mesh was proposed and an improved space-time conservation element and solution element (CE/SE) scheme with second-order accuracy was constructed. Furthermore, the application of improved CE/SE scheme was extended to detonation simulation. Three models were used for chemical reaction in gaseous detonation. And a two-fluid model was used for two-phase (gas-droplet) detonation. Shock reflections were simulated by the improved CE/SE scheme and the numerical results were compared with those obtained by other different numerical schemes. Gaseous and gas-droplet planar detonations were simulated and the numerical results were carefully compared with the experimental data and theoretical results based on C-J theory. Mach reflection of a cellular detonation was also simulated, and the numerical cellular patterns were compared with experimental ones. Comparisons show that the improved CE/SE scheme is clear in physical concept, easy to be implemented and high accurate for above-mentioned problems.
\end{abstract}

Crown Copyright @ 2009 Published by Elsevier Ltd. All rights reserved.

\section{Introduction}

Numerical simulations of detonation have been improved immensely in recent 25 years with the development of both computational methods and available computer facilities. There are two main challenges in detonation simulations. One is to calculate the process of energy release in reaction flow; the other one is to capture the strong discontinuity in detonation waves. Successful solutions to above two challenges depend on the development of chemical reaction models and numerical schemes, respectively.

Many chemical reaction models have been used in detonation simulations, such as the C-J (Chapman-Jouguet) model [1], the one-step reaction model [2], the two-step reaction model [3], the detailed chemical reaction model [4] and Sichel's two-step reaction model [5]. Algorithm, such as famous TVD (Total Variation Diminishing) scheme which treats discontinuity surface well, has been applied to detonation simulations [6]. Owing to above development, numerical simulations have been widely used to solve detonation problems in both academic explore and engineering practice. However, authors have noted that many numerical schemes lacked comprehensive verification before being applied, especially for CE/SE method (space-time conservation element and solution element method) $[7,8]$.

CE/SE method proposed originally by Chang $[9,10]$ is a new high resolution CFD (Computational Fluid Dynamics) method for con-

\footnotetext{
* Corresponding author. Tel.: +86 10 62765844; fax: +86 1062751812

E-mail address: kliu@pku.edu.cn (K. Liu).
}

servation laws. It substantially differs from other traditional numerical methods by possessing many features, e.g. unified treatment of space and time, new shock-capturing strategy, satisfaction of both local and global flux conservations in space and time by introducing conservation elements (CEs) and solution elements (SEs) etc. Simplicity, generality and accuracy are the three main advantages of the CE/SE method [9]. The construction of a CE/SE scheme includes the following steps: changing governing equations from differential form to integral form, dividing space-time region as CEs and SEs, approximating flux vectors in SEs by Taylor expansions, obtaining relation equations between the space derivatives and the time derivatives, and finally integrating the governing equations on CEs. The CE/SE method has gained great successes in simulations of jet nozzle [11] and aero-acoustics [12], steady viscous flows [13], MHD problems [14], multi-material elasticplastic flows [15]. Especially, CE/SE method has been applied to detonation simulations based on one-step chemical reaction model $[2,16]$ and detailed chemical reaction model $[7,17]$, since it is able to capture strong discontinuity surface accurately. The original $\mathrm{CE} / \mathrm{SE}$ method also has some disadvantages, such as complicated mesh structure for two-dimensional situation, and the shortage of high-accuracy schemes. Zhang et al. [18] have proposed quadrilateral and hexahedral meshes for two and three-dimensional CE/SE schemes and obtained satisfying results. Liu et al. [19] have proposed one-dimensional high-accuracy CE/SE schemes and analyzed the stability of the second-order CE/SE scheme.

The aim of present work is to construct a simple and accurate two-dimensional CE/SE scheme for both gaseous and two-phase 
detonation simulations. A new structure of CEs and SEs based on rectangular mesh and the second-order Taylor expansion in SEs is proposed. Three common chemical reaction models including two-step reaction model, detailed chemical reaction model and Sichel's two-step reaction model are used in gaseous detonation. A two-fluid model is used for simulating two-phase (gas-droplet) detonation. To verify the accuracy of the improved CE/SE scheme, shock reflections, gaseous planar detonations, Mach reflection of cellular detonations and two-phase planar detonations were simulated, respectively. All numerical results were compared with the corresponding experimental and theoretical results in detail.

\section{Chemical and physical models}

\subsection{Chemical reaction models}

Many chemical reaction models, such as the C-J model [1], the one-step reaction model [2], the two-step reaction model [3], the detailed chemical reaction model [4], Sichel's two-step reaction model [5] and some reduced chemical reaction models, have been applied to numerical simulations of detonation waves. The $\mathrm{C}-\mathrm{J}$ model has an obvious limitation due to the infinite reaction rate, though it is widely used for estimating the average properties of the detonation front. The one-step reaction model can be simplified from the two-step reaction model. Most reduced chemical reaction models are designed for special problems. Therefore, three models, that are the two-step reaction model, the detailed chemical reaction model and Sichel's two-step reaction model, are adopted in this paper for general detonation problems.

Two-step reaction model considers a complicated chemical reaction to be an induction reaction and an exothermic reaction. For both induction reaction and exothermic reaction, the progress parameters $\alpha$ and $\beta$ are unity at first, then $\alpha$ decreases to zero, $\beta$ decreases until an equilibrium state is reached. The rates $\omega_{\alpha}$ and $\omega_{\beta}$ are given as follows [20]

$\omega_{\alpha}=\frac{d \alpha}{d t}=-k_{\alpha} \rho \exp \left(-\frac{E_{a}}{R T}\right)$,

$\omega_{\beta}=\frac{d \beta}{d t}=\left\{\begin{array}{l}0(\alpha>0) \\ -k_{\beta} p^{2}\left[\beta^{2} \exp \left(-\frac{E_{\beta}}{R T}\right)-(1-\beta)^{2} \exp \left(-\frac{E_{\beta}+Q}{R T}\right)\right](\alpha \leqslant 0)\end{array}\right.$,

where $\rho$ is the mass density, $p$ the pressure, $T$ the temperature, $R$ the gas constant, $Q$ the heat release parameter, $k_{\alpha}$ and $k_{\beta}$ the constants of reaction rates, and $E_{\alpha}$ and $E_{\beta}$ the activation energies.

The detailed chemical reaction model is extensively used to describe the transformation of reactants into products at the molecular level through a large number of elementary steps. Concentrations of reactants, intermediates and products can be computed by integrating the sets of differential equations describing the rates of formation and destruction of each species. In current study, an eight-species $\left(\mathrm{H}_{2}, \mathrm{O}_{2}, \mathrm{H}, \mathrm{O}, \mathrm{HO}, \mathrm{HO}_{2}, \mathrm{H}_{2} \mathrm{O}, \mathrm{H}_{2} \mathrm{O}_{2}\right)$, twenty-reaction model [21] for a hydrogen-oxygen detonation is used. Table 1 shows the elementary chemical equations and corresponding model parameters, where $A_{k}, n_{k}$ and $E a_{k}$ are constant of reaction rate, temperature index and activation energy of the $i$ th elementary reaction step, respectively. Equations for reaction rates can be found in reference [21,22].

Sichel et al. [5] proposed a new two-step reaction model, which estimates species densities approximately and presents a generic Arrhenius form for the exothermic reaction rate $\omega_{\beta}$. Sichel's twostep reaction model supposes that all mass percentages vary linearly with respect to the progress parameter of exothermic reaction $\beta$. So the mass percentage of the $i$ th species, $C_{i}$, can be gained as
Table 1

Detailed chemical reaction model for a hydrogen-oxygen detonations (Unit: mole, s, $\mathrm{cm}, \mathrm{K}, \mathrm{cal})$.

\begin{tabular}{rlrrl}
\hline & Reaction & \multicolumn{1}{l}{$A_{k}$} & \multicolumn{1}{c}{$n_{k}$} & $E a_{k}$ \\
\hline 1 & $\mathrm{H}_{2}+\mathrm{O}_{2}=2 \mathrm{OH}$ & $1.70 \times 10^{13}$ & 0.0 & 47,780 \\
2 & $\mathrm{OH}+\mathrm{H}_{2}=\mathrm{H}_{2} \mathrm{O}+\mathrm{H}$ & $1.17 \times 10^{9}$ & 1.3 & 3626 \\
3 & $\mathrm{O}+\mathrm{OH}=\mathrm{O}_{2}+\mathrm{H}$ & $4.00 \times 10^{14}$ & -0.5 & 0 \\
4 & $\mathrm{O}+\mathrm{H}_{2}=\mathrm{OH}+\mathrm{H}$ & $5.06 \times 10^{4}$ & 2.7 & 6290 \\
5 & $\mathrm{H}+\mathrm{O}_{2}+\mathrm{M}=\mathrm{HO}_{2}+\mathrm{M}$ & $3.61 \times 10^{17}$ & -0.7 & 0 \\
6 & $\mathrm{OH}+\mathrm{HO}_{2}=\mathrm{H}_{2} \mathrm{O}+\mathrm{O}_{2}$ & $7.50 \times 10^{12}$ & 0.0 & 0 \\
7 & $\mathrm{H}+\mathrm{HO}_{2}=2 \mathrm{OH}$ & $1.40 \times 10^{14}$ & 0.0 & 1073 \\
8 & $\mathrm{O}+\mathrm{HO}_{2}=\mathrm{O}_{2}+\mathrm{OH}$ & $1.40 \times 10^{13}$ & 0.0 & 1073 \\
9 & $2 \mathrm{OH}=\mathrm{O}+\mathrm{H}_{2} \mathrm{O}$ & $6.00 \times 10^{8}$ & 1.3 & 0 \\
10 & $\mathrm{H}+\mathrm{H}+\mathrm{M}=\mathrm{H}_{2}+\mathrm{M}$ & $1.00 \times 10^{18}$ & -1.0 & 0 \\
11 & $\mathrm{H}+\mathrm{H}+\mathrm{H}_{2}=\mathrm{H}_{2}+\mathrm{H}_{2}$ & $9.20 \times 10^{16}$ & -0.6 & 0 \\
12 & $\mathrm{H}+\mathrm{H}+\mathrm{H} \mathrm{H}_{2} \mathrm{O} \mathrm{H}_{2}+\mathrm{H}_{2} \mathrm{O}$ & $6.00 \times 10^{19}$ & -1.3 & 0 \\
13 & $\mathrm{H}+\mathrm{OH}+\mathrm{M}=\mathrm{H}_{2} \mathrm{O}+\mathrm{M}$ & $1.60 \times 10^{23}$ & -2.0 & 0 \\
14 & $\mathrm{H}+\mathrm{O}+\mathrm{M}=\mathrm{OH}^{19} \mathrm{M}$ & $6.20 \times 10^{16}$ & -0.6 & 0 \\
15 & $\mathrm{O}+\mathrm{O}+\mathrm{M}=\mathrm{O}_{2}+\mathrm{M}$ & $1.89 \times 10^{13}$ & 0.0 & -1788 \\
16 & $\mathrm{H}+\mathrm{HO}=\mathrm{H}_{2}+\mathrm{O}_{2}$ & $1.25 \times 10^{13}$ & 0.0 & 0 \\
17 & $\mathrm{HO}_{2}+\mathrm{HO} \mathrm{H}_{2}=\mathrm{H}_{2} \mathrm{O}_{2}+\mathrm{O}_{2}$ & $2.00 \times 10^{12}$ & 0.0 & 0 \\
18 & $\mathrm{H}_{2} \mathrm{O}_{2}+\mathrm{M}=2 \mathrm{OH}+\mathrm{M}_{2}$ & $1.30 \times 10^{17}$ & 0.0 & 45,500 \\
19 & $\mathrm{H}_{2} \mathrm{O}_{2}+\mathrm{H}=\mathrm{HO}_{2}+\mathrm{H}_{2}$ & $1.60 \times 10^{12}$ & 0.0 & 3800 \\
20 & $\mathrm{H}_{2} \mathrm{O}_{2}+\mathrm{OH}=\mathrm{H}_{2} \mathrm{O}+\mathrm{HO}_{2}$ & $1.00 \times 10^{13}$ & 0.0 & 1800 \\
\hline
\end{tabular}

Third-body effect coefficients: (5) $\mathrm{H}_{2} \mathrm{O}=18.6, \mathrm{H}_{2}=2.86$; (10) $\mathrm{H}_{2} \mathrm{O}=0, \mathrm{H}_{2}=0$; (13) $\mathrm{H}_{2} \mathrm{O}=5.0 ;(14) \mathrm{H}_{2} \mathrm{O}=5.0$; others $=1.0$.

$C_{i}=\left(C R_{i}-C P_{i}\right) \beta+C P_{i}$,

where $C R_{i}$ and $C P_{i}$ are the mass fractions of the $i$ th species in the initial reactant and balanced product, respectively. The rate of exothermic reaction $\omega_{\beta}$ is

$\omega_{\beta}= \begin{cases}0 & \alpha>0 \\ (1-\beta) \times a \times \exp \left(-\frac{b}{T}\right)+c & \alpha \leqslant 0\end{cases}$

where $a, b, c$ are coefficients.

\subsection{Governing equations}

Governing equations for a gaseous detonation problem are twodimensional Euler equations

$\frac{\partial \mathbf{U}}{\partial t}+\frac{\partial \mathbf{E}}{\partial x}+\frac{\partial \mathbf{F}}{\partial y}=\mathbf{S}$

For two-step reaction model and Sichel's two-step reaction model, $\mathbf{U}=(\rho, \rho u, \rho v, E, \rho \alpha, \rho \beta)^{\mathrm{T}}, \mathbf{E}=\left(\rho u, \rho u^{2}+p, \rho u v,(E+p) u\right.$, $\rho \alpha u, \rho \beta u)^{\mathrm{T}}, \mathbf{F}=\left(\rho v, \rho u v, \rho v^{2}+p,(E+p) v, \rho \alpha v, \rho \beta v\right)^{\mathrm{T}}, \mathbf{S}=(0,0,0$, $\left.0, \omega_{\alpha}, \omega_{\beta}\right)^{\mathrm{T}}$, and for detailed chemical reaction model, $\mathbf{U}=\left(\rho C_{i}\right.$, $\rho u, \quad \rho v, \quad E)^{\mathrm{T}}, \quad \mathbf{E}=\left(\rho u C_{i}, \quad \rho u^{2}+p, \quad \rho u v, \quad(E+p) u\right)^{\mathrm{T}}, \quad \mathbf{F}=\left(\rho v C_{i}, \quad \rho u v\right.$, $\left.\rho v^{2}+p,(E+p) v\right)^{\mathrm{T}}, \mathbf{S}=\left(\omega_{i}, 0,0,0\right)^{\mathrm{T}}$, where $\rho$ is the mass density, $u$ and $v$ the velocity components, $p$ the pressure, $\omega_{i}$ the production rate of the $i$ th species. Total energy density $E$ is defined as

$E=\frac{p}{\gamma-1}+\frac{\rho\left(u^{2}+v^{2}\right)}{2}+\rho \beta Q$,

for two-step reaction model, and

$E=\rho h-p+\frac{\rho}{2}\left(u^{2}+v^{2}\right)$,

for detailed chemical reaction model and Sichel's two-step reaction model, respectively. Here, $\gamma$ is the specific heat ratio, $h$ the enthalpy calculated by the thermochemical relation $h=h\left(\rho_{i}, T\right)$ [22], and $p$ the pressure calculated by the state equation of perfect gas $p=\rho R T$.

In detonation simulations, the scale gap between characteristic time of chemistry and that of flow is usually significant and must be considered specially. This difficulty is so called "stiffness". The magnitude of stiffness in a problem can be weighted by Damkohler number $D a=\tau_{f} / \tau_{c}$, where $\tau_{f}$ and $\tau_{c}$ are the characteristic time scale 
of flow and chemistry, respectively. Decoupling method is applied to avoid the difficulty of stiffness in current work. That means a complete computing cycle consists of a flow step and thirty reaction steps, if $D a$ is equal to 30 .

\subsection{Two-fluid model}

Two-phase system dealing with gas-fuel detonation studies is a mixture including gas-droplet, gas-film (layer) and gas-dust. Compared with gaseous detonations, complex interaction between two phases is one of the main difficulties in numerical simulation of a two-phase detonation. In this paper, a two-fluid model is introduced for treating gas-droplet detonations.

It is assumed that the characters of a considered gas-droplet system as follows: the flow is unsteady; the initial temperature of the gas and the droplets is the same; the radii of droplets are uniform; droplets are homogenously distributed initially; the phase of droplets is considered as a continuous medium; the shape of droplets always keeps to be spherical even in process of separation, evaporation, etc; the temperature distribution in droplets is uniform; the total volume of droplets can be ignored compared with the volume of gas; the interactions between droplets are ignored; when the fuel reaches the gaseous state, chemical reactions occur and accomplish immediately; the chemical energy is absorbed only by gas, which is considered as ideal.

Under above assumptions, the governing equations for both gas phase and droplet phase are Eq. (5), and for gas phase, $\mathbf{U}=(\rho, \rho u$, $\rho v, E)^{\mathrm{T}}, \mathbf{E}=\left(\rho u, \rho u^{2}+p, \rho u v,(E+p) u\right)^{\mathrm{T}}, \mathbf{F}=\left(\rho v, \rho u v, \rho v^{2}+p,(E+\right.$ p) $v)^{\mathrm{T}}, \mathbf{S}=\left(I_{d},-F_{x}+u_{d} I_{d},-F_{y}+v_{d} I_{d},-\left(u_{d} F_{x}+v_{d} F_{y}\right)+\left(\left(u_{d}^{2}+v_{d}^{2}\right) / 2+Q\right)\right.$ $\left.I_{d}\right)^{\mathrm{T}}$; for droplet phase, $\mathbf{U}=\left(\rho_{d}, \rho_{d} u_{d}, \rho_{d} v_{d}, N\right)^{\mathrm{T}}, \mathbf{E}=\left(\rho_{d} u_{d}, \rho_{d} u_{d}^{2}, \rho_{d} u_{d} v_{d}\right.$, $\left.N u_{d}\right)^{\mathrm{T}}, \mathbf{F}=\left(\rho_{d} v_{d}, \rho_{d} u_{d} v_{d}, \rho_{d} v_{d}^{2}, N v_{d}\right)^{\mathrm{T}}, \mathbf{S}=-\left(I_{d},-F_{x}+u_{d} I_{d},-F_{y}+v_{d} I_{d}, 0\right)^{\mathrm{T}}$, where $\rho_{d}$ is the mass density of the droplet phase, $u_{d}$ and $v_{d}$ the velocity components of droplet phase, $N$ the droplet number per unit volume, $I_{d}$ the density variations during phase change, and $F_{x}$ and $F_{y}$ the force components acting on droplets. The total energy density $E$ is defined as

$E=\frac{p}{\gamma-1}+\frac{\rho\left(u^{2}+v^{2}\right)}{2}$.

$I_{d}$ can be obtained $[23,24]$ as

$I_{d}=12 r N \frac{\lambda N u\left(T-T_{d}\right)}{L}+4 \pi r^{3 / 2} \rho_{f} N\left(\frac{\rho \mu}{\rho_{f} \mu_{d}}\right)^{1 / 6}\left(\frac{\mu_{d}}{\rho_{f}}\right)^{1 / 2}\left|V-V_{d}\right|^{1 / 2}$.

The first term of Eq. (9) describes the evaporation of fuel drops, and the second term of $I_{d}$ describes the shattering of fuel drops. The force components on droplets are expressed $[23,24]$ as

$F_{x}=0.5 \pi r^{2} C_{D} \rho\left|V-V_{d}\right|\left(u-u_{d}\right) N$,

$F_{y}=0.5 \pi r^{2} C_{D} \rho\left|V-V_{d}\right|\left(v-v_{d}\right) N$, with

$\left|V-V_{d}\right|=\left[\left(u-u_{d}\right)^{2}+\left(v-v_{d}\right)^{2}\right]^{1 / 2}$,

$\operatorname{Re}=\frac{2 \rho r\left|V-V_{d}\right|}{\mu}$

$N u=2+0.6 \operatorname{Re}^{1 / 2} \operatorname{Pr}^{1 / 3}$,

$C_{D}= \begin{cases}27 R e^{-0.84}, & R e<80 \\ 0.27 R e^{0.21}, & 80 \leqslant \operatorname{Re}<10^{4} \\ 2, & R e \geqslant 10^{4}\end{cases}$

where $r$ is the radius of fuel droplets, $\lambda$ the heat conduction coefficient of gas, $T_{d}$ the temperature of fuel droplets, $L$ the heat of evaporation of fuel droplets, $\rho_{f}$ the density of fuel droplets, $\mu$ and $\mu_{d}$ the viscosity coefficients of gas phase and droplet phase, respectively. $C_{D}$ is the drag coefficient, $\mathrm{Nu}$ means Nusselt number, Re means Reynolds number and $\operatorname{Pr}$ means Prandtl number.

\section{The improved CE/SE scheme}

Different numerical CE/SE schemes can be constructed from different definitions of SEs and CEs, since flux vectors are approximated by Taylor expansions in SEs and control equations are integrated in CEs. Fig. 1 shows the space-time geometrical configuration of Chang's two-dimensional CE/SE scheme [10]. Due to the obvious disadvantage that directions of space mesh are neither perpendicular each other nor coincident with global Cartesian coordinate, this special designs of SEs and CEs are neither convenient to construct numerical schemes nor suitable for threedimensional extension.

Our improved two-dimensional CEs and SEs are demonstrated in Fig. 2. It is obvious that mesh structures shown in Fig. 2 are more general than those by Chang. In order to calculate the values of physical variables at point $P^{\prime}$, a SE and a CE (a cuboid volume related to the SE) are defined as shown in Fig. 2(b) and (c). A CE/SE scheme corresponding to the new definition of SE and CE would be easy to construct and direct to extend to three-dimensional situation.

Consider two-dimensional conservation equations

$\frac{\partial \mathbf{U}_{m}}{\partial t}+\frac{\partial \mathbf{E}_{m}\left(\mathbf{U}_{m}\right)}{\partial x}+\frac{\partial \mathbf{F}_{m}\left(\mathbf{U}_{m}\right)}{\partial y}=0$,

where $m$ is the number of the equations. Let $(j, k, n)$ denote a set of space-time mesh points, in which $n=0, \pm 1 / 2, \pm 1, \pm 3 / 2 \ldots$ for time, $j=0, \pm 1 / 2, \pm 1, \pm 3 / 2 \ldots$ for $x$ and $k=0, \pm 1 / 2, \pm 1, \pm 3 / 2 \ldots$ for $y$. Fig. 2(a) shows the projection of mesh points on the $x-y$ plane, in which time interval between mesh points $\bullet$ and $\bigcirc$ is $\Delta t / 2$ or $1 / 2$ for $n$. For every grid point $P^{\prime}(j, k, n)$, there exists a solution element $\mathrm{SE}\left(P^{\prime}\right)$ (see Fig. 2(b)), and the corresponding conservation element $\mathrm{CE}\left(P^{\prime}\right)$ is the rectangle $A C E G A^{\prime} C^{\prime} E^{\prime} G^{\prime}$ (see Fig. 2(c)).

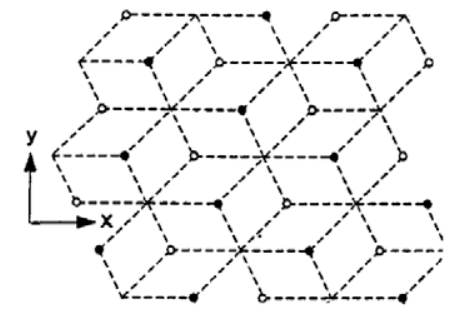

(a) Mesh points projection on the $x-y$ plane

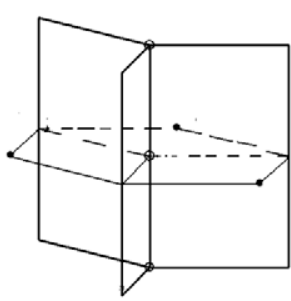

(b) SE

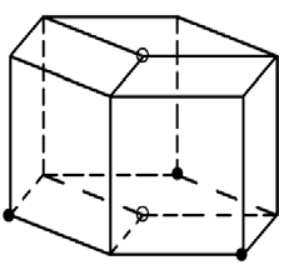

(c) $\mathrm{CEs}$

Fig. 1. Space-time geometrical configuration of the original two-dimensional CE/SE scheme (by Chang). 


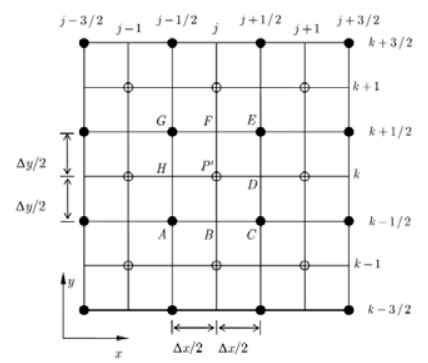

(a) Mesh points projection on the $x-y$ plane

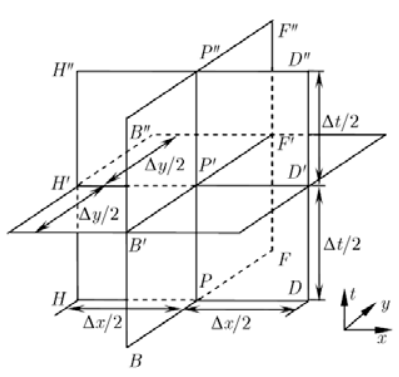

(b) SE

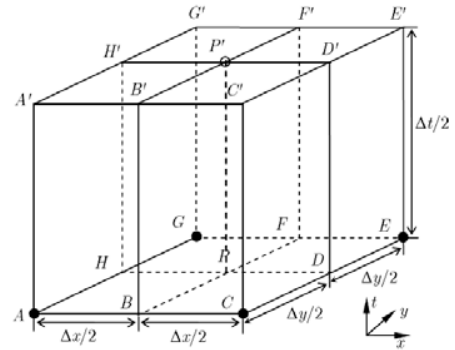

(c) CEs

Fig. 2. Space-time geometrical configuration of the improved two-dimensional CE/SE scheme.

Let $x_{1}=x, x_{2}=y, x_{3}=t$ as coordinates of a Euclidean space $E_{3}$. By using the Gauss' divergence theorem, Eq. (16) can be written in form of

$\oint_{S(V)} \mathbf{H}_{m} \cdot d s=0$,

where $S(V)$ is the boundary of the space-time region $V$ in $E_{3}$, $\mathbf{H}_{m}=\left(\mathbf{E}_{m}, \mathbf{F}_{m}, \mathbf{U}_{m}\right)$ the space-time flux vector, $d \mathbf{s}=d \sigma \cdot \mathbf{n}$, in which $d \sigma$ and $\mathbf{n}$ are the area and the unit outward normal vector of a surface element on $S(V)$.

For an arbitrary grid point $P^{\prime}$, we define a solution element $\mathrm{SE}\left(P^{\prime}\right)$ constituted by the three perpendicular planes intersecting at $P^{\prime}$ as demonstrated in Fig. 2(b). Assuming that $\mathbf{U}_{m}, \mathbf{E}_{m}$ and $\mathbf{F}_{m}$ at point $(x, y, t)$ in $\operatorname{SE}\left(P^{\prime}\right)$ are approximated by the second-order Taylor expansions at $P^{\prime}(j, k, n)$, i.e.

$$
\begin{aligned}
U_{m}(\delta x, \delta y, \delta t)_{P^{\prime}}= & \left(U_{m}\right)_{P^{\prime}}+\left(U_{m x}\right)_{P^{\prime}} \delta x+\left(U_{m y}\right)_{P^{\prime}} \delta y+\left(U_{m t}\right)_{P^{\prime}} \delta t \\
& +\frac{1}{2}\left(U_{m x x}\right)_{P^{\prime}}(\delta x)^{2}+\frac{1}{2}\left(U_{m y y}\right)_{P^{\prime}}(\delta y)^{2}+\frac{1}{2} \\
& \times\left(U_{m t t}\right)_{P^{\prime}}(\delta t)^{2}+\left(U_{m x y}\right)_{P^{\prime}} \delta x \delta y+\left(U_{m x t}\right)_{P^{\prime}} \delta x \delta t \\
& +\left(U_{m y t}\right)_{P^{\prime}} \delta y \delta t,
\end{aligned}
$$

$E_{m}(\delta x, \delta y, \delta t)_{P^{\prime}}=\left(E_{m}\right)_{P^{\prime}}+\left(E_{m x}\right)_{P^{\prime}} \delta x+\left(E_{m y}\right)_{P^{\prime}} \delta y+\left(E_{m t}\right)_{P^{\prime}} \delta t$

$$
\begin{aligned}
& +\frac{1}{2}\left(E_{m x x}\right)_{P^{\prime}}(\delta x)^{2}+\frac{1}{2}\left(E_{m y y}\right)_{P^{\prime}}(\delta y)^{2} \\
& +\frac{1}{2}\left(E_{m t t}\right)_{P^{\prime}}(\delta t)^{2}+\left(E_{m x y}\right)_{P^{\prime}} \delta x \delta y \\
& +\left(E_{m x t}\right)_{P^{\prime}} \delta x \delta t+\left(E_{m y t}\right)_{P^{\prime}} \delta y \delta t
\end{aligned}
$$

$F_{m}(\delta x, \delta y, \delta t)_{P^{\prime}}=\left(F_{m}\right)_{P^{\prime}}+\left(F_{m x}\right)_{P^{\prime}} \delta x+\left(F_{m y}\right)_{P^{\prime}} \delta y+\left(F_{m t}\right)_{P^{\prime}} \delta t$

$$
\begin{aligned}
& +\frac{1}{2}\left(F_{m x x}\right)_{P^{\prime}}(\delta x)^{2}+\frac{1}{2}\left(F_{m y y}\right)_{P^{\prime}}(\delta y)^{2} \\
& +\frac{1}{2}\left(F_{m t t}\right)_{P^{\prime}}(\delta t)^{2}+\left(F_{m x y}\right)_{P^{\prime}} \delta x \delta y \\
& +\left(F_{m x t}\right)_{P^{\prime}} \delta x \delta t+\left(F_{m y t}\right)_{P^{\prime}} \delta y \delta t,
\end{aligned}
$$

where $\delta x=x-x_{P^{\prime}}, \delta y=y-y_{P^{\prime}}, \delta t=t-t_{P^{\prime}}, x_{P^{\prime}}, y_{P^{\prime}}$ and $t_{P^{\prime}}$ are the posi-

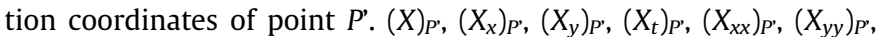

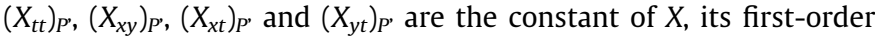
and second-order derivative respect to $x, y$ and $t$ at point $P^{\prime}$, respectively, in which $X$ denotes $\mathbf{U}_{m}, \mathbf{E}_{m}$ and $\mathbf{F}_{m}$, respectively.

Substituting Eq. (18)-(20) into Eq. (16), we can obtain

$$
\left\{\begin{array}{l}
\left(U_{m t}\right)_{P^{\prime}}=-\left(E_{m x}\right)_{P^{\prime}}-\left(F_{m y}\right)_{P^{\prime}} \\
\left(U_{m x t}\right)_{P^{\prime}}=-\left(E_{m x x}\right)_{P^{\prime}}-\left(F_{m x y}\right)_{P^{\prime}} \\
\left(U_{m y t}\right)_{P^{\prime}}=-\left(E_{m x y}\right)_{P^{\prime}}-\left(F_{m y y}\right)_{P^{\prime}} \\
\left(U_{m t t}\right)_{P^{\prime}}=-\left(E_{m x t}\right)_{P^{\prime}}-\left(F_{m y t}\right)_{P^{\prime}}
\end{array} .\right.
$$

Above equations imply that the variables in the computation are $\left(U_{m}\right)_{P^{\prime}}$ and its first and second order space derivates $\left(U_{m x}\right)_{P^{\prime}}$,

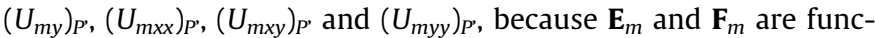
tions of $\mathbf{U}_{m}$.
Assume that flux vectors in every CEs satisfy integral conservation laws. Note that the values of physical variables on mesh points $A, C, E$ and $G$ are known. Integrating Eq. (17) on the surfaces of $C E\left(P^{\prime}\right)$

$$
\begin{aligned}
\oint_{S\left(C E\left(P^{\prime}\right)\right)} \mathbf{H}_{m} \cdot d s= & \int_{A C E G+A C C^{\prime} A^{\prime}+C E E^{\prime} C^{\prime}+E G G^{\prime} E^{\prime}+G A A^{\prime} G^{\prime}+A^{\prime} C E^{\prime} G^{\prime}} \mathbf{H}_{m} \cdot d s \\
& =\int_{A C E G} \mathbf{H}_{m} \cdot d s+\int_{A C C^{\prime} A^{\prime}} \mathbf{H}_{m} \cdot d s+\int_{C E E^{\prime} C^{\prime}} \mathbf{H}_{m} \cdot d s \\
& +\int_{E G G^{\prime} E^{\prime}} \mathbf{H}_{m} \cdot d s+\int_{G A A^{\prime} G^{\prime}} \mathbf{H}_{m} \cdot d s+\int_{A^{\prime} C E^{\prime} G^{\prime}} \mathbf{H}_{m} \cdot d s=0 .
\end{aligned}
$$

With the aid of Eq. (18)-(20), we can obtain

$$
\left(U_{m}\right)_{P^{\prime}}+\frac{\Delta x^{2}}{24}\left(U_{m x x}\right)_{P^{\prime}}+\frac{\Delta y^{2}}{24}\left(U_{m y y}\right)_{P^{\prime}}=\frac{1}{4}\left(\bar{U}+\frac{\Delta t}{\Delta x} \bar{E}+\frac{\Delta t}{\Delta y} \bar{F}\right),
$$

where

$$
\begin{aligned}
\bar{U}= & \hat{U}_{m}\left(\frac{\Delta x}{4}, \frac{\Delta y}{4}, 0\right)_{A}+\hat{U}_{m}\left(-\frac{\Delta x}{4}, \frac{\Delta y}{4}, 0\right)_{C} \\
& +\hat{U}_{m}\left(-\frac{\Delta x}{4},-\frac{\Delta y}{4}, 0\right)_{E}+\hat{U}_{m}\left(\frac{\Delta x}{4},-\frac{\Delta y}{4}, 0\right)_{G} \\
\bar{E}= & \hat{E}_{m}\left(0, \frac{\Delta y}{4}, \frac{\Delta t}{4}\right)_{A}-\hat{E}_{m}\left(0, \frac{\Delta y}{4}, \frac{\Delta t}{4}\right)_{C}-\hat{E}_{m}\left(0,-\frac{\Delta y}{4}, \frac{\Delta t}{4}\right)_{E} \\
& +\hat{E}_{m}\left(0,-\frac{\Delta y}{4}, \frac{\Delta t}{4}\right)_{G} \\
\bar{F}= & \hat{F}_{m}\left(\frac{\Delta x}{4}, 0, \frac{\Delta t}{4}\right)_{A}+\hat{F}_{m}\left(-\frac{\Delta x}{4}, 0, \frac{\Delta t}{4}\right)_{C}-\hat{F}_{m}\left(-\frac{\Delta x}{4}, 0, \frac{\Delta t}{4}\right)_{E} \\
& -\hat{F}_{m}\left(\frac{\Delta x}{4}, 0, \frac{\Delta t}{4}\right)_{G}
\end{aligned}
$$

in which

$$
\begin{aligned}
\hat{U}_{m}(\delta x, \delta y, \delta t)_{P^{\prime}}= & \left(U_{m}\right)_{P^{\prime}}+\left(U_{m x}\right)_{P^{\prime}} \delta x+\left(U_{m y}\right)_{P^{\prime}} \delta y+\left(U_{m t}\right)_{P^{\prime}} \delta t \\
& +\frac{1}{6}\left(U_{m x x}\right)_{P^{\prime}}(\delta x)^{2}+\frac{1}{6}\left(U_{m y y}\right)_{P^{\prime}}(\delta y)^{2}+\left(U_{m x y}\right)_{P^{\prime}} \delta x \delta y,
\end{aligned}
$$

$\hat{E}_{m}(\delta x, \delta y, \delta t)_{P^{\prime}}=\left(E_{m}\right)_{P^{\prime}}+\left(E_{m x}\right)_{P^{\prime}} \delta x+\left(E_{m y}\right)_{P^{\prime}} \delta y+\left(E_{m t}\right)_{P^{\prime}} \delta t$

$$
+\frac{1}{6}\left(E_{m y y}\right)_{P^{\prime}}(\delta y)^{2}+\frac{1}{6}\left(E_{m t t}\right)_{P^{\prime}}(\delta t)^{2}+\left(E_{m y t}\right)_{P^{\prime}} \delta y \delta t,
$$

$\hat{F}_{m}(\delta x, \delta y, \delta t)_{P^{\prime}}=\left(F_{m}\right)_{P^{\prime}}+\left(F_{m x}\right)_{P^{\prime}} \delta x+\left(F_{m y}\right)_{P^{\prime}} \delta y+\left(F_{m t}\right)_{P^{\prime}} \delta t$

$$
+\frac{1}{6}\left(F_{m x x}\right)_{P^{\prime}}(\delta x)^{2}+\frac{1}{6}\left(F_{m t t}\right)_{P^{\prime}}(\delta t)^{2}+\left(F_{m x t}\right)_{P^{\prime}} \delta x \delta t .
$$

Eq. (23) shows that the current second-order derivates $\left(U_{m x x}\right)_{P}$, and $\left(U_{m y y}\right)_{P^{\prime}}$ at $P^{\prime}$ must be known firstly for solving $\left(U_{m}\right)_{P}$. With the linearly estimated value in $\operatorname{SE}\left(P^{\prime}\right)$ approximated from the last half time step, the current second-order derivates $\left(U_{m x x}\right)_{P}$ and $\left(U_{m y y}\right)_{P}$, can be expressed as 


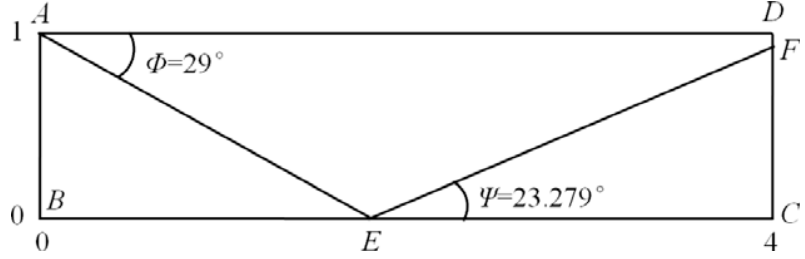

Fig. 3. Structural scheme of the shock reflection problem.

$\left(U_{m x x}\right)_{P^{\prime}}=\frac{\left(U_{m x}^{\prime}\right)_{C}-\left(U_{m x}^{\prime}\right)_{A}+\left(U_{m x}^{\prime}\right)_{E}-\left(U_{m x}^{\prime}\right)_{G}}{2 \Delta x}$,

$\left(U_{m y y}\right)_{P^{\prime}}=\frac{\left(U_{m y}^{\prime}\right)_{G}-\left(U_{m y}^{\prime}\right)_{A}+\left(U_{m y}^{\prime}\right)_{E}-\left(U_{m y}^{\prime}\right)_{C}}{2 \Delta y}$,

where $\left(U_{m x}^{\prime}\right)=\left(U_{m x}\right)+\frac{\Delta t}{2}\left(U_{m x t}\right),\left(U_{m y}^{\prime}\right)=\left(U_{m y}\right)+\frac{\Delta t}{2}\left(U_{m y t}\right)$.

The cross derivates can be computed from

$\left(U_{m x y}\right)_{P^{\prime}}=\left(U_{m y x}\right)_{P^{\prime}}=\frac{\left(U_{m x y}\right)_{P^{\prime}}^{\prime}+\left(U_{m y x}\right)_{P^{\prime}}^{\prime}}{2}$

where $\left(U_{m x y}\right)_{P^{\prime}}^{\prime}=\frac{\left(U_{m x}^{\prime}\right)_{G}-\left(U_{m x}^{\prime}\right)_{A}+\left(U_{m x}^{\prime}\right)_{E}-\left(U_{m x}^{\prime}\right)_{C}}{2 \Delta y},\left(U_{m y x}\right)_{P^{\prime}}^{\prime}=\frac{\left(U_{m y}^{\prime}\right)_{C}-\left(U_{m y}^{\prime}\right)_{A}+\left(U_{m y}^{\prime}\right)_{E}-\left(U_{m y}^{\prime}\right)_{C}}{2 \Delta x}$.

Using the continuous condition at point $A^{\prime}, C^{\prime}, E^{\prime}$ and $G^{\prime}$, the left and the right derivatives of $U_{m}$ respect to $x$ and $y$ can be gained as

$\left(U_{m x}\right)_{P^{\prime}}^{-}=-\frac{1}{\Delta x}\left[U_{m}\left(0,0, \frac{\Delta t}{2}\right)_{A}+U_{m}\left(0,0, \frac{\Delta t}{2}\right)_{G}-2\left(U_{m}\right)_{P^{\prime}}\right]$,

$\left(U_{m x}\right)_{P^{\prime}}^{+}=+\frac{1}{\Delta x}\left[U_{m}\left(0,0, \frac{\Delta t}{2}\right)_{C}+U_{m}\left(0,0, \frac{\Delta t}{2}\right)_{E}-2\left(U_{m}\right)_{P^{\prime}}\right]$,

$\left(U_{m y}\right)_{P^{\prime}}^{-}=-\frac{1}{\Delta y}\left[U_{m}\left(0,0, \frac{\Delta t}{2}\right)_{A}+U_{m}\left(0,0, \frac{\Delta t}{2}\right)_{C}-2\left(U_{m}\right)_{P^{\prime}}\right]$,

$\left(U_{m y}\right)_{P^{\prime}}^{+}=+\frac{1}{\Delta y}\left[U_{m}\left(0,0, \frac{\Delta t}{2}\right)_{E}+U_{m}\left(0,0, \frac{\Delta t}{2}\right)_{G}-2\left(U_{m}\right)_{P^{\prime}}\right]$.

To avoid numerical instability in discontinuous cases, the derivates should be rewritten in a form of average of variables marked with '+' and '-' in Eq. (33)-(36).

$\left(U_{m x}\right)_{P^{\prime}}=\frac{\left.\left|\left(U_{m x}\right)_{P^{\prime}}^{+}\right|\left(U_{m x}\right)_{P^{\prime}}^{-}+\mid U_{m x}\right)_{P^{\prime}}^{-} \mid\left(U_{m x}\right)_{P^{\prime}}^{+}}{\left.\left|\left(U_{m x}\right)_{P^{\prime}}^{+}\right|+\mid U_{m x}\right)_{P^{\prime}}^{-} \mid}$,

$\left(U_{m y}\right)_{P^{\prime}}=\frac{\left|\left(U_{m y}\right)_{P^{\prime}}^{+}\right|\left(U_{m y}\right)_{P^{\prime}}^{-}+\left|\left(U_{m y}\right)_{P^{\prime}}^{-}\right|\left(U_{m y}\right)_{P^{\prime}}^{+}}{\left|\left(U_{m y}\right)_{P^{\prime}}^{+}\right|+\left|\left(U_{m y}\right)_{P^{\prime}}^{-}\right|}$.

\section{Applications}

\subsection{Shock reflections}

Shock wave reflection is a classical benchmark problem [25]. By imposing suitable upstream conditions, an oblique incident and a reflected shock wave will appear above a flat plate. Fig. 3 shows the structural scheme of this problem. The domain is a $4 \times 1$ rectangle containing $200 \times 50$ uniform meshes. The left boundary conditions are $\rho=1.0, u=2.9, v=0, p=0.7143$; the upper boundary conditions are $\rho=1.7, u=2.6193, v=-0.50632, p=1.5282$; the right boundary is free; and the bottom boundary is solid. The total computing time is 2.5 with a uniform time step $\Delta t=0.002$.

Fig. 4 shows the density contours computed by the improved CE/ SE scheme, which agrees with the exact solution (Fig. 3) well. In order to evaluate accuracy of the improved CE/SE scheme further, we also calculated the shock reflection problem under the same conditions using Chang's CE/SE scheme [10], second-order MUSCL scheme and first-order Reo scheme. Fig. 5(a) shows the distribution of the pressure coefficient $C_{p}\left(=2\left(p / p_{\infty}-1\right) /\left(\gamma M_{\infty}^{2}\right)\right)$ at $y=0.5$ by different numerical schemes, and the exact solution is also provided. Fig. 5(b) gives a local enlargement vision of the pressure coefficient. It is can be seen from Fig. 5 that the accuracy of the improved CE/SE scheme is highest, and that of Chang's CE/SE scheme is higher than first-order Roe scheme and second-order MUSCL scheme with the same computing meshes. Fig. 5 also shows numerical results using the improved CE/SE scheme with $100 \times 25$ meshes, $400 \times 100$ meshes and $800 \times 200$ meshes, respectively. The numerical results converge to the exact solution as the number of computing meshes increases.

The case of shock reflections shows that the improved CE/SE method not only is a high-accuracy numerical method, but also keeps the advantages of the original CE/SE method and enhances its numerical accuracy.

\subsection{Gaseous planar detonations}

The computations in this section model a detonation propagating in a stoichiometric $\mathrm{H}_{2}-\mathrm{O}_{2}$ gas, and the initial pressure and the temperature are 1 atm and $298 \mathrm{~K}$, respectively. Channel walls are considered as solid boundaries. Assume that there is no energy loss on the walls during a detonation propagating. The detonation wave is generated by an igniting on the left with a high initial pressure and temperature as 28 atm and $3874 \mathrm{~K}$, respectively. Those initial conditions make DDT (Deflagration-to-Detonation Transition) process complete within $0.5 \mu \mathrm{s}$, so we can study detonations clearly without considering the deflagration propagation and the DDT process.

Computing parameters of stoichiometric $\mathrm{H}_{2}-\mathrm{O}_{2}$ gas for the three chemical reaction models are given as follows.

1. Two-step reaction model: $Q=1.33 \times 10^{7} \mathrm{~J} / \mathrm{kg}, k_{\alpha}=3.0 \times 10^{8} \mathrm{~m}^{3} / \mathrm{kg} /$ $\mathrm{s}, k_{\beta}=1.875 \times 10^{-5} \mathrm{~m}^{4} / \mathrm{N}^{2} / \mathrm{s}, E_{\alpha}=2.261 \times 10^{7} \mathrm{~J} / \mathrm{kg}, E_{\beta}=4.6151 \times$ $10^{6} \mathrm{~J} / \mathrm{kg}[20]$.

2. Detailed chemical reaction model: see Table 1 [21].

3. Sichel's two-step reaction model: $a=1.2 \times 10^{8}, b=8 \times 10^{3}, c=0$ [5]; $C P\left(\mathrm{H}_{2}, \mathrm{O}_{2}, \mathrm{H}, \mathrm{O}, \mathrm{HO}, \mathrm{HO}_{2}, \mathrm{H}_{2} \mathrm{O}, \mathrm{H}_{2} \mathrm{O}_{2}\right)=\left(1.978 \times 10^{-2}\right.$, $0.10042, \quad 4.49 \times 10^{-3}, 3.27 \times 10^{-2}, \quad 0.14027,2.3209 \times 10^{-4}$, $0.70209,2.2772 \times 10^{-5}$ ) which are calculated from the detailed chemical reaction model.

Fig. 6(a)-(c) show the pressure profiles using the two-step reaction model, the detailed chemical reaction model and Sichel's

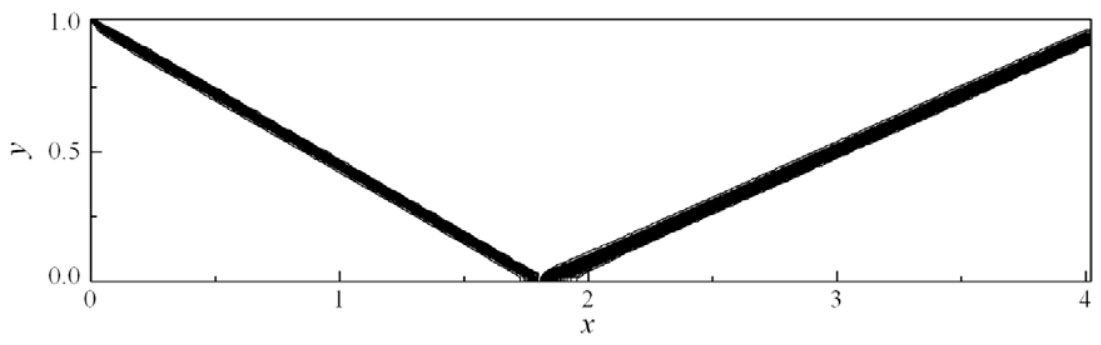

Fig. 4. Density contours by improved CE/SE scheme $(200 \times 50)$. 


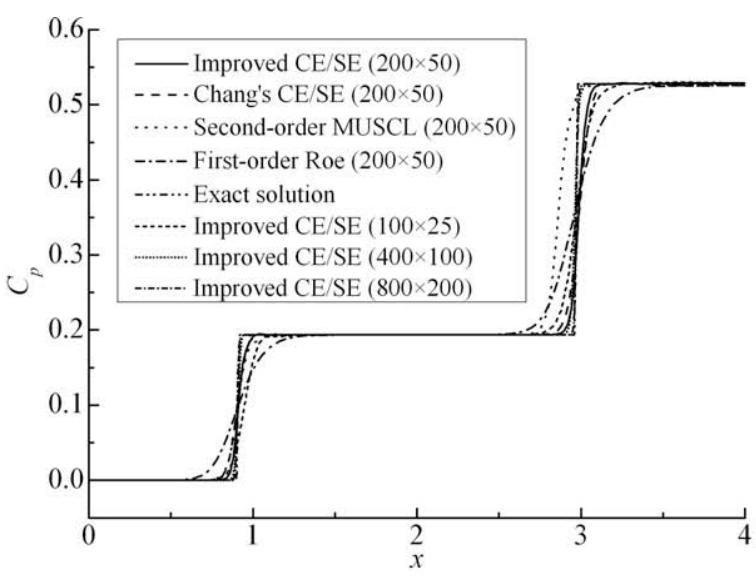

(a) The whole $x$ axis

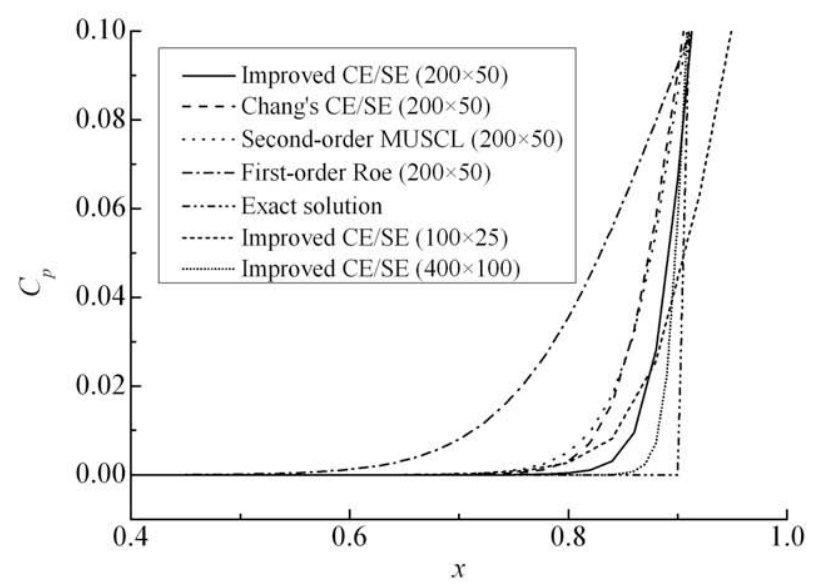

(b) Local enlargement

Fig. 5. Pressure coefficient at $y=0.5$ by different numerical schemes $(200 \times 50)$.

reaction model, respectively. All of the three figures are typical pressure profiles of a planar detonation wave. The highest pressure appears in detonation front, the pressure decreases in rarefaction zone and keeps constant in stable zone. Table 2 gives characteristic quantities of detonation waves coming from five different ways (experiment, C-J theory, and three numerical simulations by the improved CE/SE scheme using two-step, detailed and Sichel's two-step reaction models, respectively) under the same initial conditions. Relative errors of detonation velocities calculated by the three chemical reaction models are all limited to 3\% compared to the experimental result. As to detonation temperature and $\mathrm{C}-\mathrm{J}$ pressure, the detailed chemical reaction model agrees best with the experimental data. For peak pressure, the two-step reaction model agrees best with the experimental data.

In order to verify the improved CE/SE scheme further, we simulate $\mathrm{H}_{2}-\mathrm{O}_{2}$ detonations at different equivalence ratios using the detailed chemical reaction model. Fig. 7(a)-(c) show comparisons of the three different physical variables, such as the detonation velocities, the $\mathrm{C}-\mathrm{J}$ pressures and the von Neumann peak pressures, obtained from our numerical results, experiment and C-J theory, respectively. The comparisons show that detonation velocities by $\mathrm{C}-\mathrm{J}$ theory and simulations are both agree well with that from experiments, but for peak pressure and $\mathrm{C}-\mathrm{J}$ pressure at low equivalence ratios situations, the numerical results are more accurate than that by $\mathrm{C}-\mathrm{J}$ theory.

This case indicates that the improved CE/SE scheme can simulate gaseous planar detonation waves successfully and accurately using the three chemical reaction models.

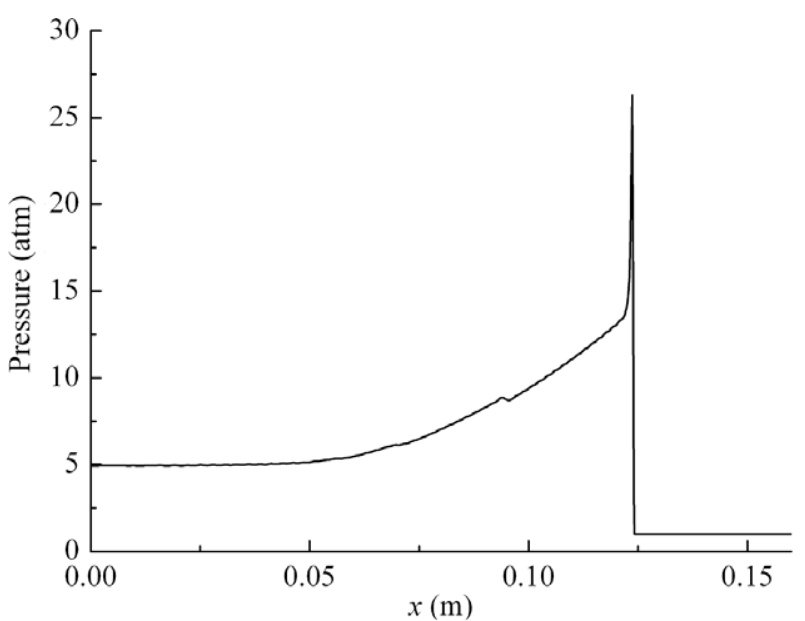

(a) Two-step reaction model

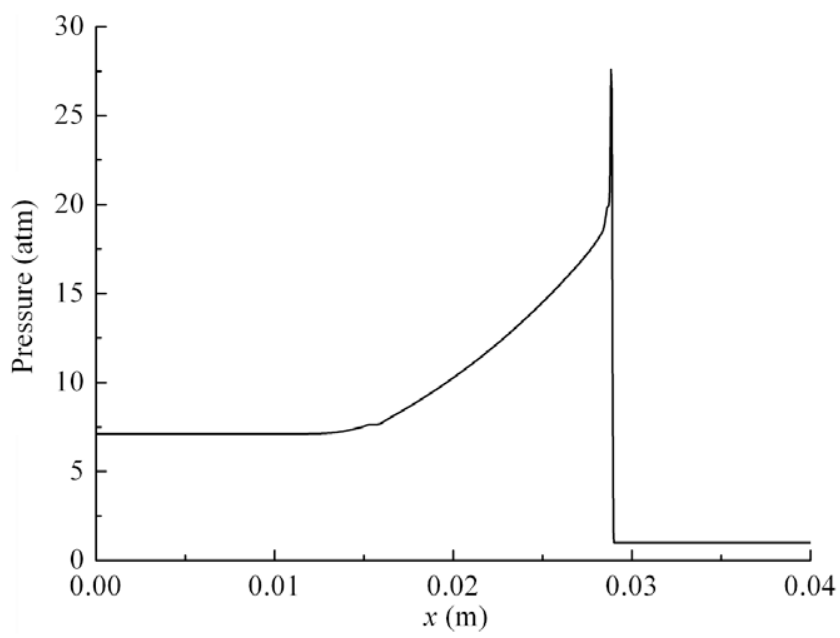

(b) Detailed chemical reaction model

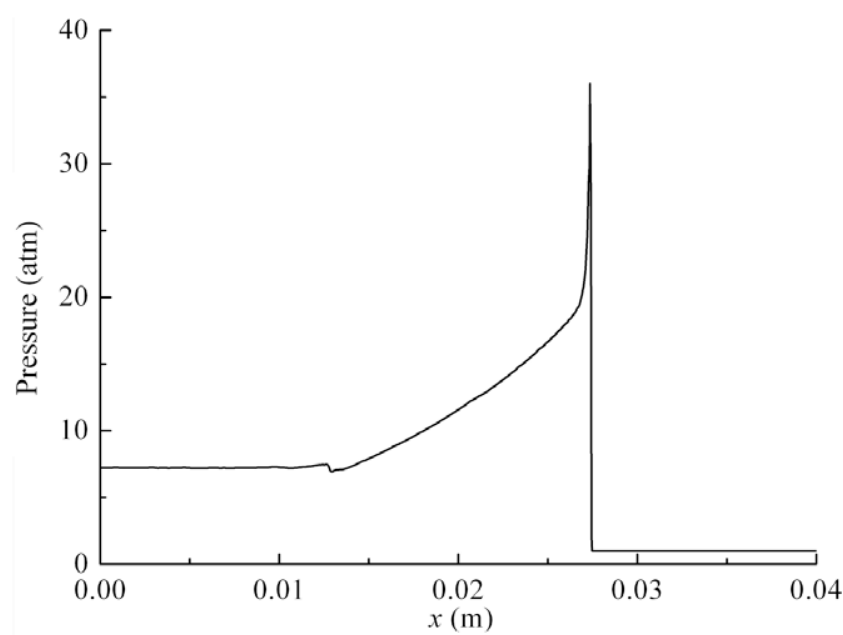

(c) Sichel's two-step chemical model

Fig. 6. Pressure profiles by different chemical reaction models (1000 meshes).

\subsection{Mach reflection of cellular detonations}

Reflection of detonation wave on a wedge is one of the most fundamental problems relating interactions between detonation wave and surrounding structure [27-29]. In this section, we simulated Mach reflection of cellular detonations and captured cellular 
Table 2

Detonation properties by different ways (1000 meshes).

\begin{tabular}{|c|c|c|c|c|}
\hline & $\begin{array}{l}\text { Detonation } \\
\text { velocity } \\
(\mathrm{m} / \mathrm{s})\end{array}$ & $\begin{array}{l}\text { Temperature } \\
\text { (K) }\end{array}$ & $\begin{array}{l}\mathrm{C}-\mathrm{J} \\
\text { pressure } \\
(\mathrm{atm})\end{array}$ & $\begin{array}{l}\text { Peak } \\
\text { pressure } \\
\text { (atm) }\end{array}$ \\
\hline Experiment [26] & 2825 & 3583 & 18.6 & 27.1 \\
\hline C-J model [26] & 2853 & - & 18.59 & 34.16 \\
\hline Two-step reaction model & 2784 & 2466 & 12.55 & 28.5 \\
\hline $\begin{array}{l}\text { Detailed chemical reaction } \\
\text { model }\end{array}$ & 2826 & 3421 & 18.60 & 31.4 \\
\hline Sichel's two-step reaction model & 2908 & 4037 & 19.03 & 35.1 \\
\hline
\end{tabular}

patterns on tube wall. Computational models are the same as Section 4.2 except that a $19.3^{\circ}$ wedge is putted in the tube. The boundary of the wedge is also a solid.

Fig. 8(a)-(d) show the cellular patterns observed in experiment [27] and numerical simulations using the two-step reaction model, the detailed chemical model and Sichel's two-step reaction model, respectively. It is found that all the three numerical results can describe the basic phenomena of cellular detonation reflections, such as regular numerical cellular pattern at the left of the wedge, changes of the size and the shape of cells between the triple-point trajectory and the wedge. Table 3 lists characteristic parameters of cellular patterns and detonation reflections. Fig. 9 shows a schematic sketch identifying characteristic parameters of the cellular pattern. Comparisons in Table 3 show that the numerical results by the three chemical reaction models all agree well with the experimental results in quantity.

The case of Mach reflection of cellular detonations indicates that the improved CE/SE scheme can simulate cellular structure and reflection of gaseous detonations accurately using all the three chemical reaction models.

\subsection{Two-phase planar detonations}

In this section, two-phase planar detonations in a gas-droplet system are simulated. Initial pressure and temperature are $1 \mathrm{~atm}$ and $298 \mathrm{~K}$, respectively. Fuel droplets are made of $\mathrm{C}_{3} \mathrm{H}_{6} \mathrm{O}$ and with a uniform radius $50 \mu \mathrm{m}$. Channel walls are still considered as solid boundaries. Detonation wave is generated by igniting in the left with a high initial pressure and temperature as $20 \mathrm{~atm}$ and $2980 \mathrm{~K}$, respectively. Other computing parameters of a stoichiometric $\mathrm{O}_{2}-\mathrm{C}_{3} \mathrm{H}_{6} \mathrm{O}$ are given as below: $\lambda=0.1 \mathrm{~W} / \mathrm{K} / \mathrm{m}, L=5.27 \times 10^{5} \mathrm{~J} /$ $\mathrm{kg}, \quad \rho_{f}=860 \mathrm{~kg} / \mathrm{m}^{3}, \quad \mu=2.07 \times 10^{-5}$ Pas, $\mu_{d}=3.5 \times 10^{-4}$ Pas, $Q=$ $3.17 \times 10^{7} \mathrm{~J} / \mathrm{kg}, \operatorname{Pr}=0.74$.

Fig. 10(a)-(d) show the distributions of the pressure, the temperature, the density of gas phase and the density of droplet phase in $x$ direction at $t=1 \times 10^{-3} \mathrm{~s}$. It can be seen that the profiles of the pressure, the temperature and the density of the gas phase are similar to those of gaseous detonations, but values of physical quantities are higher than those of gaseous detonations. That means the improved $\mathrm{CE} / \mathrm{SE}$ scheme can simulate two-phase planar detonations using the two-fluid model. The higher values of physical quantities are due to the high chemical energy of the liquid fuel and that is one of the main reasons for two-phase detonation research. Fig. 10(d) shows that the length of chemical reaction zone is about $0.06 \mathrm{~m}$, which is much longer than that in a gaseous detonation. This phenomenon was also observed in experiments [30].

It is assumed that chemical reactions finish immediately when fuel droplets are converted into gaseous state in our two-fluid model. The rate of state transformation is determined by Eq. (9). So the rate of chemical reaction is related to $I_{d}$. Comparing the characteristic time of $I_{d}$ (physical process of fuel droplet) with that of chemical reactions, it can be proved that the assumption is reasonable.

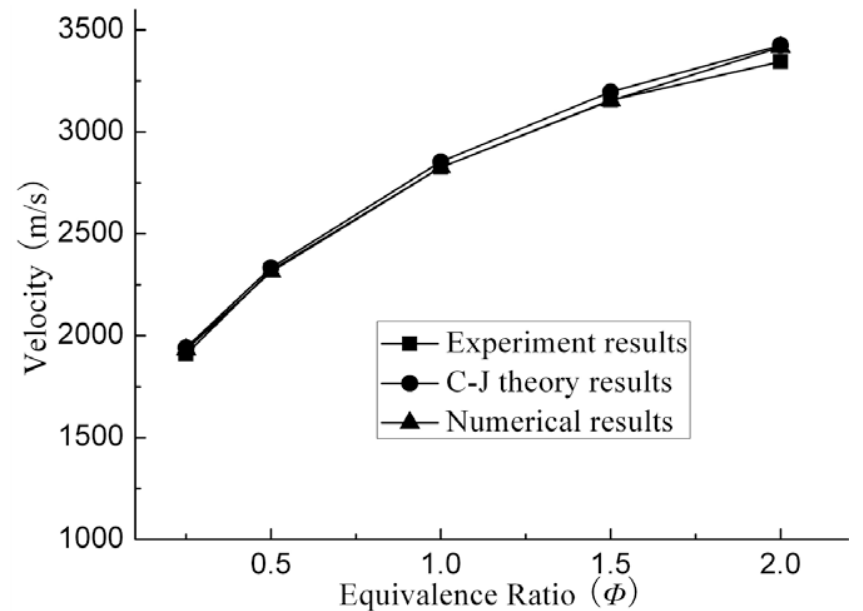

(a) Detonation velocity

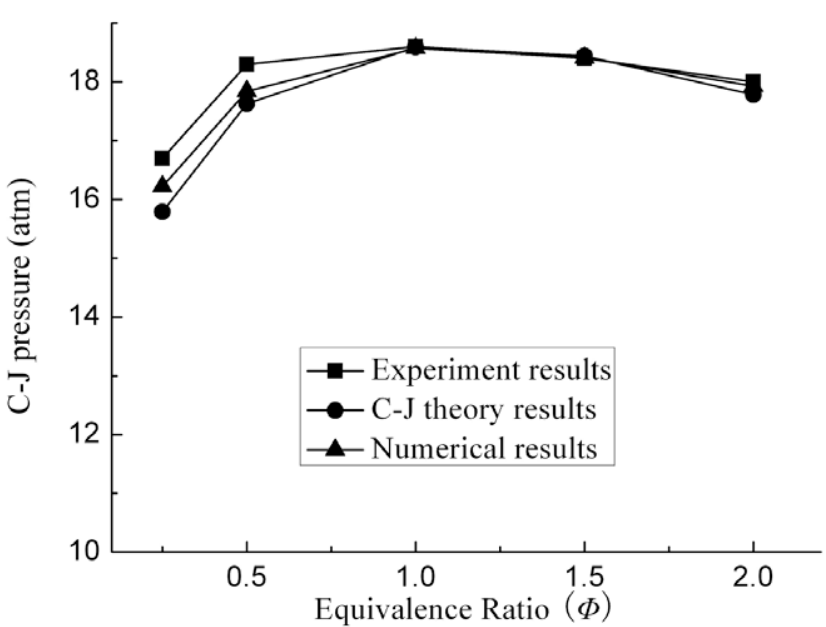

(b) $\mathrm{C}-\mathrm{J}$ pressure

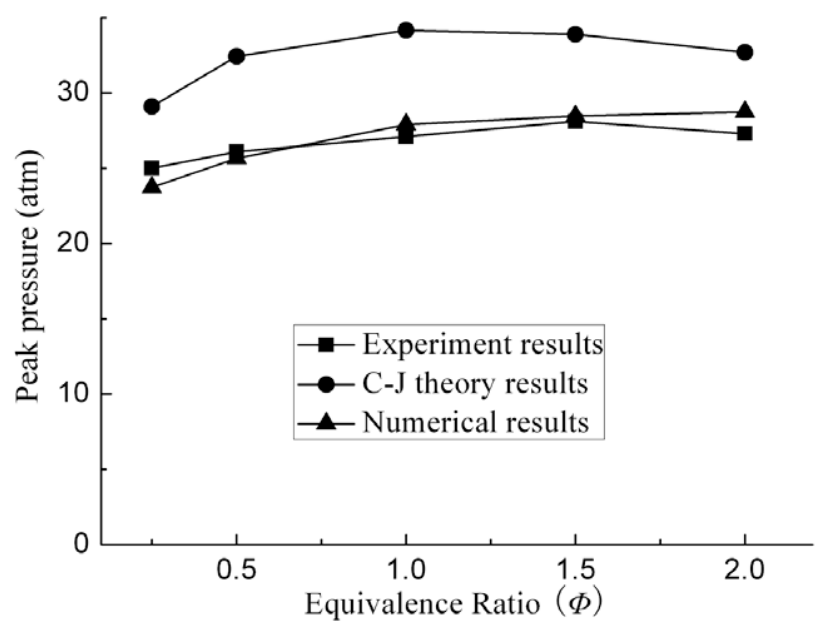

(c) Peak pressure

Fig. 7. Numerical results compared with experimental and theoretical results by

The variation of droplet radius respect to time can be computed

$\frac{d r}{d t}=\frac{9 \lambda N u\left(T-T_{d}\right)}{\pi r \rho_{d} L}+3\left(\frac{\rho \mu}{\rho_{d} \mu_{d}}\right)^{\frac{1}{6}}\left(\frac{\mu_{d}}{\rho_{f}}\right)^{\frac{1}{2}}\left|V-V_{d}\right|^{1 / 2} r^{-\frac{1}{2}}$ 


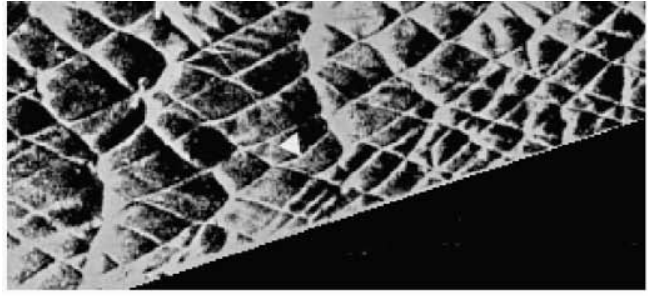

(a) Experiment (2001, Guo C M, Zhang D L)

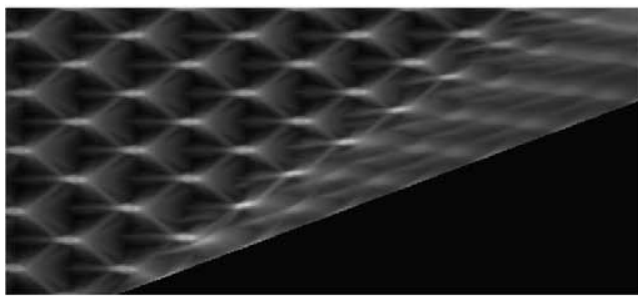

(c) Detailed chemical reaction model $(400 \times 200$ meshes $)$

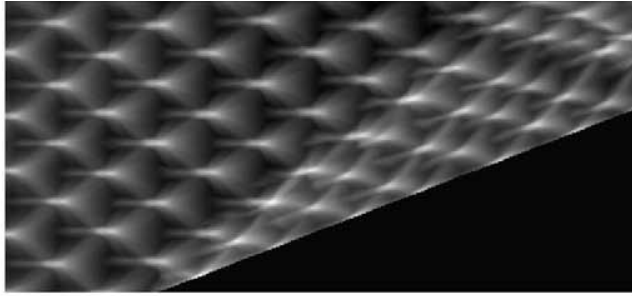

(b) Two-step reaction model $(400 \times 200$ meshes $)$

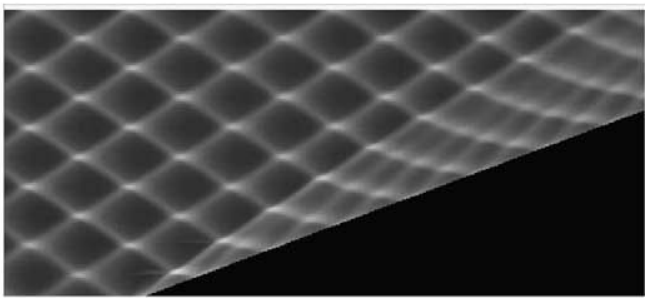

(d) Sichel's two-step reaction model $(400 \times 200$ meshes $)$

Fig. 8. Cellular patterns of detonation waves over the $19.3^{\circ}$ wedge.

Table 3

Characteristic parameters of cellular patterns and detonation reflections.

\begin{tabular}{|c|c|c|c|c|c|}
\hline & $\begin{array}{l}\text { Cell } \\
\text { width/ cell } \\
\text { length }\end{array}$ & $\begin{array}{l}\text { Exit } \\
\text { angle } \\
\left({ }^{\circ}\right)\end{array}$ & $\begin{array}{l}\text { Entrance } \\
\text { angle }\left({ }^{\circ}\right)\end{array}$ & $\begin{array}{l}\text { Angle of } \\
\text { transverse } \\
\text { wave trace } \\
\left({ }^{\circ}\right)\end{array}$ & $\begin{array}{l}\text { Angle between } \\
\text { the triple-point } \\
\text { trajectory and } \\
\text { the wedge }\left(^{\circ}\right)\end{array}$ \\
\hline Experiment & $0.5-0.6$ & $5-10$ & $32-40$ & $\approx 30$ & $11.5-13.0$ \\
\hline Two-step & 0.59 & 9.2 & 33.0 & 30.5 & $\approx 13.1$ \\
\hline Sichel's two-step & 0.60 & 11.2 & 31.5 & 29.0 & $\approx 11.3$ \\
\hline Detailed & 0.51 & 9.5 & 38.2 & 28.5 & $\approx 12.2$ \\
\hline
\end{tabular}

From Fig. 10 the approximate values of physical quantities can be obtained as: $\rho \approx 1.0 \mathrm{~kg} / \mathrm{m}^{3},\left|V-V_{d}\right| \approx 1000 \mathrm{~m} / \mathrm{s}$ and $\left(T-T_{d}\right) \approx$ $2200 \mathrm{~K}$, then $d r / d t \approx 1.0 \mathrm{~m} / \mathrm{s}$ calculated from Eq. (39). That means the characteristic time of $I_{d}$ is $5 \times 10^{-5} \mathrm{~s}$, if the radius of fuel droplets is equal to $50 \mu \mathrm{m}$. The rate of chemical reactions is obtained as $1.0 \times 10^{5} \mathrm{~kg} / \mathrm{m}^{3} / \mathrm{s}$ from Eq. (2). The fuel droplet concentration is about $5 \%$. So the characteristic time of chemical reactions is equal to $5 \times 10^{-7} \mathrm{~s}\left(\ll 5 \times 10^{-5} \mathrm{~s}\right)$. The comparison implies that the characteristic time of $I_{d}$ is much larger than that of chemical reaction. Therefore the chemical reaction can finish within the characteristic time of $I_{d}$.

In order to verify the accuracy of the improved CE/SE scheme in two-phase detonations, we simulated two-phase planar detonations in $\mathrm{O}_{2}-\mathrm{C}_{6} \mathrm{H}_{14}$ and $\mathrm{O}_{2}-\mathrm{C}_{10} \mathrm{H}_{20}$ system with different equivalence ratios and droplet radii. Table 4 shows detonation velocities at different computational conditions with corresponding results from C-J theory and experiments [30,31]. The experimental errors in gas-droplet detonations are much larger than that in gaseous detonations, because experimental conditions of gas-droplet detonations, such as the sizes and distribution of droplets, are quite difficult to be well-proportioned. But people prefer to trust in experimental results because errors of $\mathrm{C}-\mathrm{J}$ theory which ignores two-phase effects are larger [30]. Table 4 also shows relative errors $\left(=\left(v-v_{\text {experiment }}\right) / v\right)$ of the velocities from numerical simulations and the $\mathrm{C}-\mathrm{J}$ model respect to that from experiments. It can be found that the numerical velocities are all more accurate than C-J velocities. The relative errors exceed $10 \%$ in only two cases, and we believe that the reason should also be the uncertain experimental results. As to the whole results, the relative errors of numerical simulations could be considered as less than $10 \%$.

The case of two-phase planar detonations provides an accurate evidence for using the improved CE/SE scheme and the two-fluid

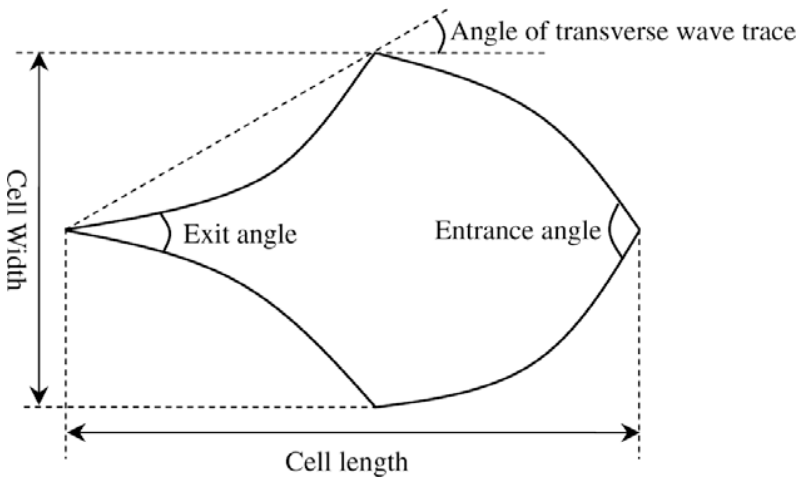

Fig. 9. Schematic sketch identifying characteristic parameters of the cellular pattern.

model to simulate two-phase detonation problems. As we know, it is the first time to use CE/SE method to solve two-phase detonations.

\section{Conclusions}

In this paper, we developed an improved CE/SE scheme for detonation simulations. This scheme is based on the rectangular mesh and the second-order Taylor expansion. Three chemical reaction models and their governing equations were introduced for gaseous detonation simulations, and a two-fluid model was introduced for two-phase detonation simulations. Obviously, other chemical and physical models can be added to the current frame work conveniently.

The main advantages of the current scheme are clear in physical concept, easy to be extended to three-dimensional situations, accurate to capture the shock wave and convenient to implement boundary conditions. In the applications of detonation simulations, this scheme combines chemical reaction models with physics models conveniently and treats source items easily. The numerical results show that the improved CE/SE scheme can simulate gaseous and two-phase detonation problems accurately. The improved CE/SE scheme can also be applied to detonation simulations for academic explore and engineering extensively.

In future, we will develop a three-dimensional improved CE/SE scheme for detonation simulations. Some specific detonation problems, such as DDT process, PDE (Pulse Detonation Engine) perfor- 


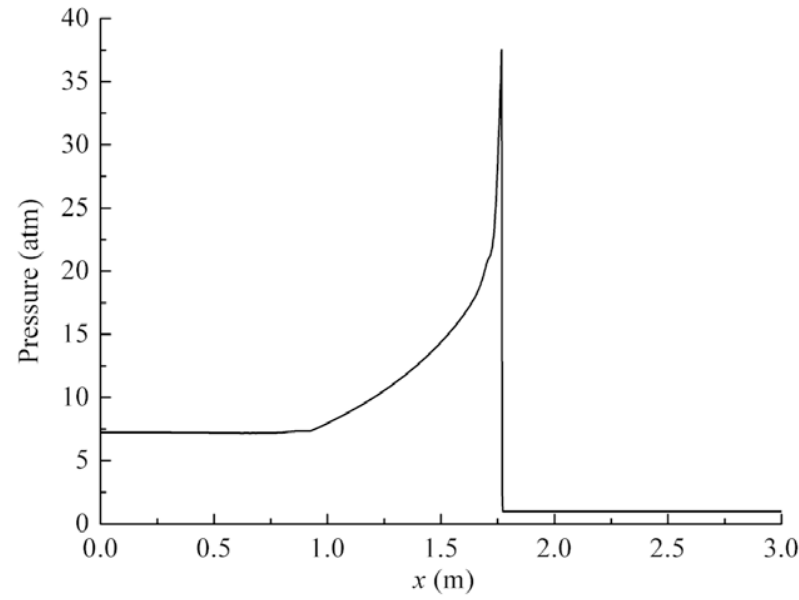

(a) Pressure profile

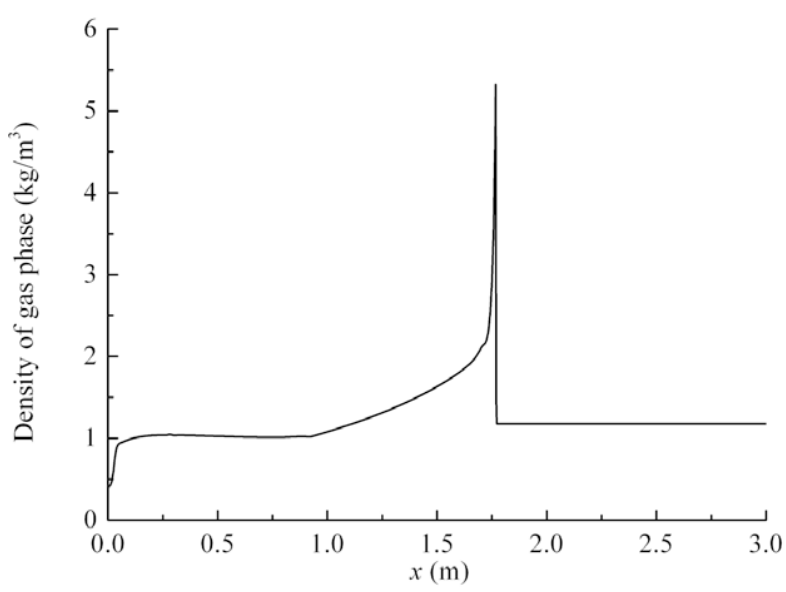

(c) Density profile of gas phase

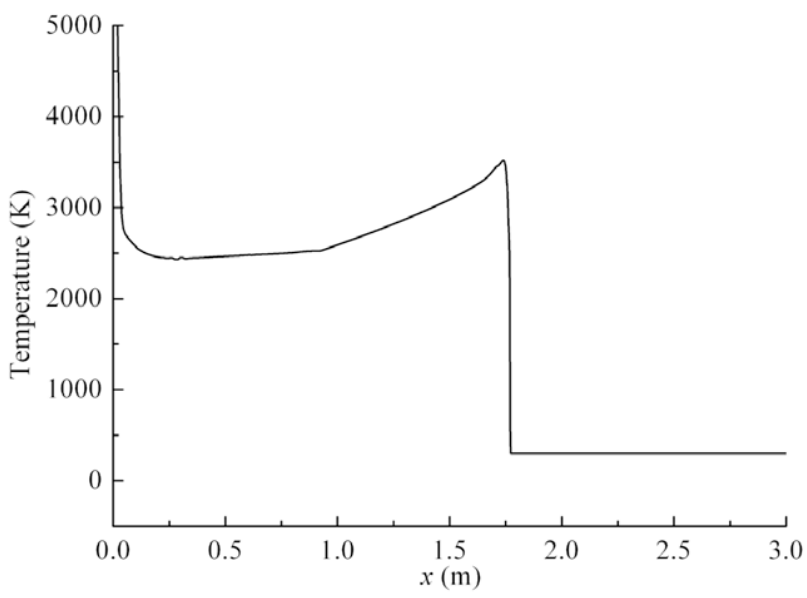

(b) Temperature profile

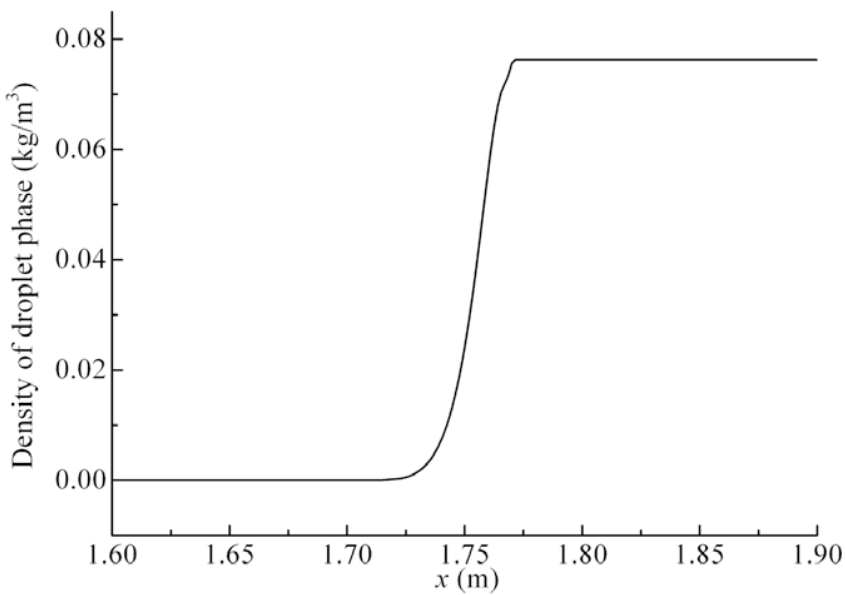

(d) Local density profile of droplet phase

Fig. 10. Physical quantity profiles of $\mathrm{O}_{2}-\mathrm{C}_{3} \mathrm{H}_{6} \mathrm{O}$ two-phase detonation wave at $t=1 \times 10^{-3} \mathrm{~s}$ (2000 meshes).

Table 4

Detonation velocities at different computational conditions (2000 meshes).

\begin{tabular}{|c|c|c|c|c|c|}
\hline Liquid fuel & Droplet radius $(\mu \mathrm{m})$ & Equivalence ratio & Simulation $(\mathrm{m} / \mathrm{s})$, relative error & Experiment $(\mathrm{m} / \mathrm{s})$ & $\mathrm{C}-\mathrm{J}$ theory $(\mathrm{m} / \mathrm{s})$, relative error \\
\hline $\mathrm{C}_{6} \mathrm{H}_{14}$ & $20-30$ & 0.41 & $1544.83,-7.50 \%$ & 1670 & $1950,16.77 \%$ \\
\hline $\mathrm{C}_{6} \mathrm{H}_{14}$ & $20-30$ & 0.49 & $1671.30,-2.83 \%$ & 1720 & $2040,18.60 \%$ \\
\hline $\mathrm{C}_{6} \mathrm{H}_{14}$ & $20-30$ & 0.56 & $1773.92,4.35 \%$ & 1700 & $2090,22.94 \%$ \\
\hline $\mathrm{C}_{6} \mathrm{H}_{14}$ & $20-30$ & 0.68 & $1935.89,8.76 \%$ & 1780 & $2170,21.91 \%$ \\
\hline $\mathrm{C}_{10} \mathrm{H}_{20}$ & 145 & 1.0 & $1946.93,-8.59 \%$ & 2130 & $2380,11.74 \%$ \\
\hline $\mathrm{C}_{10} \mathrm{H}_{20}$ & 375 & 0.914 & $1996.72,7.93-10.32 \%$ & $1810-1850$ & $2260,22.16-24.86 \%$ \\
\hline $\mathrm{C}_{10} \mathrm{H}_{20}$ & 1300 & 0.23 & $1169.97,-6.40-20.62 \%$ & $970-1250$ & $1780,42.40-83.51 \%$ \\
\hline
\end{tabular}

mance, will also be investigated using the improved CE/SE scheme and appropriate chemical and physical models.

\section{Acknowledgements}

The authors gratefully acknowledge the financial support of the National Natural Science Foundation of China (Grant Nos. 10732010, 10572002 and 20490206).

\section{References}

[1] Bird PF, Duff RE, Schott GL. A Fortranfap code for computing normal shock and detonation wave parameters in gases. LA 2980: Los Alamos Scientific Laboratory Report; 1964.

[2] Zhang ZC, John Yu ST, Hao H, Chang SC. Direct calculations of two-and threedimensional detonations by an extended CE/SE method. AIAA 2001-0476; 2001.
[3] Taki S, Fujiwara T. Numerical analysis of two-dimensional nonsteady detonations. AIAA J 1978;16(1):73-7.

[4] Oran ES, Weber JW, Stefaniw EI, Lefebvre MH, Anderson JD. A numerical study of a two-dimensional $\mathrm{H}_{2}-\mathrm{O}_{2}-\mathrm{Ar}$ detonation using a detailed chemical reaction model. Combust Flame 1998;113:147-63.

[5] Sichel M, Tonello NA, Oran ES, Jones DA. A two-step kinetics model for numerical simulation of explosions and detonations in $\mathrm{H}_{2}-\mathrm{O}_{2}$ mixtures. Proc $\mathrm{R}$ Soc Lond A Math Phys Eng Sci 2002;458(2017):49-82.

[6] Hu XY, Zhang DL, Khoo BC, Jiang ZL. The structure and evolution of a twodimensional $\mathrm{H}_{2} / \mathrm{O}_{2} / \mathrm{Ar}$ cellular detonation. Shock Waves 2005;14(12):37-44.

[7] Wang B, Hao H, John Yu ST. Direct calculation of wave implosion for detonation initiation in pulsed detonation engines. AIAA 2005-1306; 2005.

[8] Zhang ZC, John Yu ST, Hao H, Jorgenson PCE. Direct calculations of plume dynamics of a pulse detonation engine by the CE/SE method. AIAA 2001-3614 2001.

[9] Chang SC. The method of space-time conservation element and solution element - a new approach for solving the Navier-Stokes and Euler equations. J Comput Phys 1995;119:295-324. 
[10] Chang SC, Wang XY, Chow CY. The space-time conservation element and solution element method: a new high-resolution and genuinely multidimensional paradigm for solving conservation laws. J Comput Phys 1999;156:89-136.

[11] Wang XY, Chang SC, Jorgenson PCE. Prediction of sound waves propagating through a nozzle without/with a shock wave using the space-time CE/SE method. AIAA 2000-0222; 2000.

[12] Liu M, Wang JB, Wu KQ. The direct aero-acoustics simulation of flow around a square cylinder using the $\mathrm{CE} / \mathrm{SE}$ scheme. J Algorithms Comput Technol 2007;1(4):525-37.

[13] Guo YH, Hsu AT, Wu J, Yang ZG, Oyediran A. Extension of CE/SE method to 2D viscous flows. Comput Fluids 2004;33:1349-61.

[14] Zhang M, John Yu ST, Henry Lin SC, Chang SC, Blankson I. Solving the MHD equations by the space-time conservation element and solution element method. J Comput Phys 2006;214(2):599-617.

[15] Wang JT, Liu KX, Zhang DL. An improved CE/SE scheme for multi-material elastic-plastic flows and its applications. Comput Fluids 2009;38:544-51.

[16] Hao H, John Yu ST, Zhang ZC. Direct calculations of one-, two-, and threedimensional detonations by the CESE method. AIAA 2005-0229; 2005.

[17] Wang B, John Yu ST. Direct calculation of spherical detonation initiation of $\mathrm{H}_{2} /$ $\mathrm{O}_{2} /$ Ar mixtures by the CESE method. AIAA 2004-0793; 2004.

[18] Zhang ZC, John Yu ST, Chang SC. A space-time conservation element and solution element method for solving the two- and three-dimensional unsteady Euler equations using quadrilateral and hexahedral meshes. J Comput Phys 2002;175:168-99.

[19] Liu KX, Wang JT. Analysis of high accuracy conservation-element and solutionelement schemes. Chin Phys Lett 2004;21(11):2085-8.
[20] Taki S, Fujiwara T. Numerical simulation on the establishment of gaseous detonation. Prog Astronaut Aeronaut 1984;94:186-200.

[21] Kee RJ, Rupley FM, Meeks E, Miller JA. CHEMKIN-III: A FORTRAN chemical kinetics package for the analysis of gas-phase chemical and plasma kinetics. UC-405, SAND96-8216; 1996.

[22] McBride BJ, Zehe MJ, Gordon S. NASA Glenn coefficients for calculating thermodynamic properties of individual species. NASA/TP 2002-211556; 2002.

[23] Ranger AA, Nicholls JA. Aerodynamic shattering of liquid drops. AIAA J 1969;7(2):285-90.

[24] Eidelman S, Burcat A. Evolution of a detonation wave in a cloud of fuel droplet: part I. Influence of igniting explosion. AIAA J 1980;18(9):1103-9.

[25] Yee HC, Warming RF, Harten A. Implicit total variation diminishing (TVD) schemes for steady-state calculations. J Comput Phys 1985;57(33):327-60.

[26] Nettleton MA. Gaseous detonations: their nature, effects and control. London, New York: Chapman and Hall; 1987.

[27] Guo CM, Zhang DL, Xie W. The mach reflection of a detonation based on soot track measurements. Combust Flame 2001;127:2051-8.

[28] Akbar R. Mach reflection of gaseous detonations. Ph.D. thesis. Rensselaer Polytechnic Institute; 1997.

[29] Ohyag S, Obara T, Nakata F, Hoshi S. A numerical simulation of reflection processes of a detonation wave on a wedge. Shock Waves 2000;10:185-90.

[30] Roy GD, Frolov SM, Borisov AA, Netzer DW. Pulse detonation propulsion: challenges, current status, and future perspective. Prog Energy Combust Sci 2004;30:545-672.

[31] Dabora EK, Ragland KW, Nicholls JA. A study of heterogeneous detonations. Astronaut Acta 1966;12:9-16. 